\title{
Prevalence of Human Papilloma Virus in HIV-Positive and HIV-Negative Patients in the State of Bahia. A Pilot Study
}

Conceição Queiroz $^{1}$, Ana Gabriela Travassos
Eduardo Studart' $^{2}$, José Bouzas Araújo Filho, $^{3}$,
Carla Kruchewsky Sarno $^{4}$ and Carla Cristiane Pinheiro

\author{
Department of Gynecology, Obstetrics and Human \\ Reproduction ${ }^{1}$; Department of Pathology ${ }^{2}$; Department \\ of Statistics ${ }^{3}$, Federal University of Bahia; State Center \\ for Oncology-CICAN $N^{4}$ Salvador, Bahia, Brazil
}

Human Papilloma Virus (HPV) plays a central role in the development of cervical cancer. However, other coexisting factors, such as HIV infection, must be present for this to occur. We evaluated the prevalence of HPV in HIV-positive and HIV-negative patients in the city of Salvador , Bahia, Brazil, and determined the most prevalent types of HPV in these patients. Fifty-five cases were selected from among patients attending three institutions providing cervical pathology services in the city of Salvador. HIV testing (Elisa/WB), HPV-DNA testing by PCR, colposcopy, cytology and biopsy were carried out in all patients. The histopathological results were classified as follows: 11 cases were normal/negative for neoplasia, 15 were diagnosed as cervical intraepithelial neoplasia grade 1 (CIN 1), 10 were CIN 2,15 cases were CIN 3 and there were four cases of invasive squamous cell carcinoma. Among the 55 patients studied, 43 tested positive for HPV-DNA and 20 for HIV. All HIV-positive patients were positive for HPV-DNA. The most prevalent types of HPV were HPV 16, 52, 58, 53, 54, 33 and 51, and there was little difference between the groups of HIV-positive and HIV-negative patients with respect to the type of HPV encountered. The HIV-positive patients were found to be infected with a greater number of types of HPV than the HIV-negative patients. This study corroborates the existence of regional variations in the distribution of certain types of HPV, which is probably due to the particular ethnic constitution found in this region of Brazil.

Key Words: Human papilloma virus (HPV), human immunodeficiency virus (HIV), cervical intraepithelial neoplasias (CIN), cervical invasive carcinoma.

Invasive squamous cell cervical cancer develops from well-defined precancerous lesions, which can potentially progress to invasive disease if they are not detected early and treated. There is epidemiological and molecular evidence that infection by human papilloma virus (HPV) plays an important role in the development of uterine cancer [1]. However, infection by oncogenic HPV types is necessary but insufficient to cause cervical cancer [2], the association of other Received on 30 April 2004; revised 14 September 2004. Address for correspondence: Dr. Conceição Queiroz. Rua Marechal Floriano, 106, Apt. 1102, Canela. Zip code: 40110010 Salvador, Bahia, Brazil.

Telephone/Fax: (55-71) 235-4594, 332-5310.

The Brazilian Journal of Infectious Diseases 2004;8(5):356-362 (C) 2004 by The Brazilian Journal of Infectious Diseases and Contexto Publishing. All rights reserved. coexisting factors in addition to HPV is necessary to modulate the transition from cervical infection to cancer.

Some coexisting factors inherent to HPV influence the risk of progression of CINs and the development of cervical cancer. This risk is related to the HPV genotype, variants, viral load, persistence, and integration of the viral DNA of the host genome [1,3-6]. Currently accepted coexisting factors related to the host are high parity, prolonged use of oral contraceptives [7-11], smoking [12,13], and sexually transmitted diseases (STD), such as herpes simplex virus type 2, Chlamydia trachomatis [14,15] and, especially, acquired immunodeficiency syndrome (AIDS), [16,17].

The first report relating cervical intraepithelial neoplasia (CIN) to HIV was published by Bradbier [18]. Other publications followed and, based on this information, invasive squamous cell carcinoma was 
added to the Center for Disease Control and Prevention (CDC)'s definition of AIDS in January 1993 [19]. It has been found that women infected with HIV have a high prevalence of HPV infection and cervical intraepithelial neoplasia (CIN), [16,17,20,21]. The two infections share common epidemiological data: they are both considered sexually transmitted diseases, they share sexual behavior risk factors, and younger women and ethnic minorities are at greater risk.

More than 100 types of HPV have been identified (HPV database: http://hpv-web.lanl.gov/), of which around 30 types are related to anal-genital infections [22]. Of these, 15 types: $16,18,31,33,35,39,45$, $51,52,56,58,59,68,73$ and 82 , are considered highly oncogenic [23], being involved in more than $95 \%$ of cases of cervical cancer [2]. Types 6, 11, 40, 42, $43,44,54,61,70,72$ and 81 are commonly associated with condyloma acuminate and low-grade cervical lesions, flat condyloma or low-grade cervical intraepithelial neoplasia, with characteristics of papilloma virus infection [23,24]. In addition, HPV 26, 53 and 66 are types that probably bear a high risk [23]. The outcome of the infection depends on the type of virus, its anatomical localization, the influence of tissue factors [25,26] and the action of coexisting factors [27]. The forms of HPV infection may be latent, subclinical or clinical. Cervical intraepithelial neoplasias (CINs) and invasive carcinoma are considered clinical manifestations of infection.

We evaluated the prevalence of HPV in HIVpositive and HIV-negative patients in the city of Salvador, Bahia, and investigated the types of HPV most frequently found in these patients.

\section{Material and Methods}

Fifty-five patients were selected from among women who presented an atypical transformation zone (ATZ) and an atypical cytology result, or negative cytology with persistent ATZ ( $\geq 6$ months) between October 1999 and March 2001 at the State Center for Oncology - CICAN (State Health Authority), at the Gynecology outpatient clinic (Infectious Diseases Unit) of the Professor Edgar Santos Hospital, Federal University of Bahia (UDAI-HUPES-UFBA), or at the private clinic of one of the authors (CQ), in the city of Salvador, Bahia.

Patients gave their written, informed consent to participate in the study, and they answered a questionnaire, in which sociodemographic and clinical information was solicited. Patients were submitted to an HIV test (Elisa/WB) at the Retroviral Laboratory of the Professor Edgar Santos Hospital, or at CICAN, and all were submitted to colposcopy, cytology and biopsy. Colposcopic biopsies were carried out using Gaylor-Medina forceps, or by loop electrosurgical excision procedure (LEEP), depending on the extent of the ATZ.

HPV-DNA was detected by enzymatic amplification, and it was carried out using polymerase chain reaction (PCR). Before colposcopy was carried out, the ectocervix and endocervix were scraped with a sterile brush, cell dispersion was performed in TE (10mM Tris, 1mM EDTA, pH 7.4) and the sample frozen at $-20^{\circ} \mathrm{C}$. The material was sent to the Ludwig Research Institute for Cancer in São Paulo where PCR was carried out using MY09/11 primers.

\section{Results}

\section{Sociodemographic characteristics}

The mean age of the patients in this study was 37 years (range $19-82$ years), the majority $(\sim 67 \%)$ being between 21 and 41 years of age. Sixty-three percent were mulattos, while $20 \%$ were black and $15 \%$ were white. With respect to marital status, half were single, $37 \%$ married, $10 \%$ widowed and $2 \%$ divorced. Fortyfive percent of the patients came from outside the state capital, whereas $42 \%$ were from the capital and $12 \%$ came from other states in Brazil. In this study, $11.7 \%$ of the patients were illiterate, $55 \%$ had completed primary education, $25 \%$ had completed high school and $8.3 \%$ had attended a university, two of whom had already graduated. In the survey of occupations, $70 \%$ worked outside the home and $30 \%$ were housewives. 
When the groups of HIV-positive and HIVnegative patients were compared, no significant differences were found between the two groups with respect to ethnic group, marital status, region of birth, education level or occupation.

\section{Histopathological examination}

The 55 cases were classified according to histopathological examination as follows: 11 patients tested normal/negative for neoplasia (including chronic cervicitis and squamous metaplasia), 15 cases were classified as cervical intraepithelial neoplasia grade 1 (CIN1), 10 cases of CIN2, 15 cases of CIN3 and four cases of invasive squamous cell carcinoma.

\section{PCR for HPV testing}

Among the 55 patients, HPV-DNA testing by PCR was positive in 43. Among the cases diagnosed as CIN or carcinoma, $91 \%$ were HPV-DNApositive, whereas among the cases with a normal histological diagnosis, $40 \%$ were positive, and $70 \%$ of these patients had lesions detect by colposcopy. Among the cases that tested negative for HPV, six patients had a negative biopsy for neoplasia, two were classified as CIN1, two as CIN3 and there were two cases of carcinoma. Among the patients who tested positive for HPV, two types of low-risk HPV were identified, types 6 and 54, as well as 14 types considered to be of high oncogenic risk, types $16,18,31,33,35,39,45,51,52,56,58,59,68$ and 73 , and one considered of probable high risk, type 53 .

The most frequent types of HPV were HPV 16 (30\%), HPV52 (11\%), HPV58 (7.9\%), HPV53 (6.3\%), HPV56 (6.3\%), HPV51 (5.4\%), HPV31 (4.8\%), HPV33 (4.8\%), HPV35 (4.8\%), HPV51 (4.8\%), HPV6 (4.8\%) and HPV54 (3.2\%). The other types, HPV18, 39, 45, 59, 68, 73 and 84, were detected only once in each case. Table 1 shows the histology results, as well as the results of HPV-DNA and HIV testing for the 55 patients.

\section{HIV testing}

Of the 55 patients in this study, 20 were HIV-positive and all HIV-positive patients tested positive for HPVDNA. The most frequent types of HPV found among these patients were: HPV16, 52 and 56. Among the HIV-negative patients, the most frequent types found were HPV16, 58 and 52 (Table 2).

Among the group of HIV-positive patients, women were found to be infected with up to five different types of HPV infection, whereas among the $35 \mathrm{HIV}$-negative patients, only one or two types of HPV infection were found per patient (Table 3).

\section{Discussion}

Among the patients in this study who were positive for HPV-DNA, low risk HPV types 6 and 54 were found in four cases, in one of which only type 6 was found. Type 53, present in four cases, is currently considered likely to be oncogenic [23]. The remaining types were classified as high oncogenic risk HPV. The most prevalent type was HPV16, present in $30 \%$ of cases. In 16 cases, this HPV type was the only type found. Muñoz et al. found HPV16 to be the most common type of HPV infection in all countries in which their study was carried out, with infection rates varying from $43.9 \%$ in the Philippines to $72.4 \%$ in Morocco [23]. HPV16 appears to begin progression earlier and more consistently than the other viral types, and when isolated it is the most important factor related to the progression of the disease, since HPV16 is associated with greater persistence than the other types [22].

The other types of HPV most frequently encountered in the patients were HPV52, 58, 53 and 56; these results are not in agreement with the data reported by Muñoz et al, who found types 16, 18, 45, $31,33,52,58$ and 35 to be most frequent, listed in decreasing order, including cases of infection by one or various viral types [23]. In Brazil, Rabelo-Santos et al., in Goiânia (Goiás), found $76 \%$ positivity for HPVDNA in 74 patients with a diagnosis of CIN3 and cervical cancer, the most frequent types being 16 , 
Table 1. Distribution of cases according to histological results, HIV, and HPV

\begin{tabular}{lccccc}
\hline Histology & $\mathbf{N}$ & HIV $^{+}$ & HIV $^{-}$ & HPV $^{+}$ & HPV $^{-}$ \\
\hline Normal & 11 & 4 & 7 & 5 & 6 \\
CIN 1 & 15 & 7 & 8 & 13 & 2 \\
CIN 2 & 10 & 6 & 4 & 10 & 0 \\
CIN 3 & 15 & 3 & 12 & 13 & 2 \\
Invasive cancer & 4 & 0 & 4 & 2 & 0 \\
Total & $\mathbf{5 5}$ & $\mathbf{2 0}$ & $\mathbf{3 5}$ & $\mathbf{4 3}$ & $\mathbf{1 0}$ \\
\hline
\end{tabular}

CIN 1: cervical intraepithelial neoplasia grade 1 .

Table 2. Frequency of types of HIV with respect to type of HPV

\begin{tabular}{|c|c|c|c|c|}
\hline \multicolumn{3}{|c|}{ HIV $^{+}$} & \multirow[b]{2}{*}{$\mathbf{N}$} & \multirow[b]{2}{*}{$\%$} \\
\hline Type & $\mathbf{N}$ & $\%$ & & \\
\hline 6 & 1 & 2.9 & 2 & 7,1 \\
\hline 16 & 6 & 17.1 & 13 & 46.4 \\
\hline 18 & 1 & 2.9 & & \\
\hline 31 & 1 & 2.9 & 2 & 7.1 \\
\hline 33 & 2 & 5.7 & 1 & 3.6 \\
\hline 35 & 2 & 5.7 & 1 & 3.6 \\
\hline 39 & 1 & 2.9 & & \\
\hline 45 & 1 & 2.9 & & \\
\hline 51 & 3 & 8.6 & & \\
\hline 52 & 4 & 11.4 & 3 & 10.7 \\
\hline 53 & 2 & 5.7 & 2 & 7.1 \\
\hline 54 & 2 & 5.7 & & \\
\hline 56 & 4 & 11.4 & & \\
\hline 58 & 1 & 2.9 & 4 & 14.3 \\
\hline 59 & 1 & 2.9 & & \\
\hline 68 & 1 & 2.9 & & \\
\hline 73 & 1 & 2.9 & & \\
\hline 84 & 1 & 2.9 & & \\
\hline Total & 35 & 100.0 & 28 & 100.0 \\
\hline
\end{tabular}


Table 3. Distribution of number of types of HPV among HIV-positive and HIV-negative patients according to histological diagnosis

\begin{tabular}{|c|c|c|c|c|c|c|c|c|c|c|}
\hline \multirow[t]{2}{*}{ Number of HPV types } & \multicolumn{2}{|c|}{ Normal } & \multicolumn{2}{|c|}{ CIN1 } & \multicolumn{2}{|c|}{$\begin{array}{l}\text { CIN2 } \\
\text { HIV }\end{array}$} & \multicolumn{2}{|c|}{ CIN3 } & \multicolumn{2}{|c|}{$\mathbf{C a}$} \\
\hline & + & - & + & - & + & - & + & - & + & - \\
\hline One type & 1 & 3 & 4 & 1 & 3 & 3 & 7 & 3 & & 2 \\
\hline Two types & & & 2 & 1 & 1 & 3 & 2 & & & \\
\hline Three types & & 1 & & 1 & & & & & & \\
\hline Five types & & & & 2 & & & & & & \\
\hline
\end{tabular}

Types presented: $6^{*}, 16,18,31,33,35,39,45,51,52,53 * *, 54 *, 56,58,59,68$, and 73 .

(*low risk HPV ** probably high risk HPV).

CIN: cervical intraepithelial neoplasia grade.

followed by 33, 18 and 31 [28]. Unlike the two previously-mentioned studies [23, 28], in our study we had only one case that tested positive for HPV18 (2.3\%).

Among the cases in our study with diagnosis of CIN or carcinoma, 91\% were positive for HPV-DNA, whereas among the cases with a normal histological diagnosis, $40 \%$ were positive, although $70 \%$ of these patients had lesions detectable by colposcopy. In a study carried out in Brazil, among 169 patients with cervical squamous cell carcinoma, $97 \%$ tested positive for HPV-DNA by PCR, whereas among the control group, $17.3 \%$ were positive [29].

It has been suggested that more than one infectious agent may act synergically in the development of cervical cancer. However, epidemiological studies have failed to clarify whether STD are markers of high-risk behavior or coexisting factors of transmission. In this study, all HIV-positive patients were positive for HPVDNA. The most prevalent types of HPV among HIVpositive patients were: HPV16, 52, 51, 56, 54, 33, 35 and 53. Among HIV-negative patients, the most prevalent types were: HPV16, 58, 52, 31, 6 and 53. Gonçalves et al. detected types 16 and 18 (30.5\%) in Santos (São Paulo), followed by types 61 and 53 (24.4\%) in 141 HIV-positive patients [30]. In a recent study in São Paulo among 208 HIV-positive patients, $100 \%$ were positive for HPV-DNA, type 6 being the most prevalent (39.2\%), followed by HPV51 (31.9\%),
HPV11 (26.0\%), HPV18 (24.0\%) and HPV 16 (22.5\%), [17].

Our study corroborates the existence of regional variations in the distribution of certain types of HPV, even when we compare our data with that of other studies carried out in central-west or southeast Brazil [17]. These findings in this region of Brazil are probably due to the particular ethnic constitution of the area, with a predominance of individuals of Afro ethnicity. These differences should be taken into consideration in diagnostic testing, since the commercially available tests (Hybrid Capture, Digene) are unable to detect types 53, 73 and 84, which were found in 4, 1 and 1 of our patients, respectively, as well as in patients of other studies carried out in Brazil [30,31].

Up to five different viral types were detected in HIV-positive patients, whereas HIV-negative patients presented a maximum of two simultaneous types of HPV. Greater rates of oncogenic HPV and multiple types of HPV are more frequently found in HIV-positive women $[17,32]$. This greater number of types of HPV detected in HIV-positive women is more frequently associated with the persistence or activation of preexisting infections, due to reduced immunity rather than through the acquisition of a new infection [33].

We analyzed a small number of patients, and it is impossible to draw epidemiological conclusions from this sample. However, it is the first study carried out in Bahia, and it is the beginning of a broader study involving 
multiple departments. This approach may become important in the prevention of cervical cancer, as well as in the elaboration of specific vaccines for each region.

\section{Acknowledgments}

The authors thank Dr. Luisa Lina Villa of the Ludwig Institute for Research in Cancer, São Paulo, Brazil for carrying out the PCR testing.

\section{References}

1. Ho G.Y., Burk R.D., Kein S., et al. Persistent genital human papillomavirus infection as a risk factor for persistent cervical dysplasia. J Nat Cancer Inst 1995;87:1365-71.

2. Walboomers J.M., Jacobs M.V., Manos M.M. Human papillomavirus is a necessary cause of invasive cervical cancer worldwide. J Pathol 1999; 189:12-9.

3. Josefsson A.M., Magnusson P.K.E., Ylotalo N., et al. Viral load of human papillomavirus 16 as a determinant for development of cervical carcinoma in situ: a nested case-control study. Lancet 2000;355:2189-93.

4. Villa L.L., Sichero L., Rahal P., et al. Molecular variants of human papillomavirus types 16 and 18 preferentially associated with cervical neoplasia. J Gen Virol 2000;81:2959-68.

5. Schlecht N. F., Kulaga S., Robitaille J., et al. Persistent human papillomavirus infection as a predictor of cervical intraepithelial neoplasia. JAMA 2001;286:3106-14.

6. Schlecht N. F., Trevisan A., Duarte-Franco E., et al. Viral load as a predictor of cervical intraepithelial neoplasia. Int J Cancer 2003; 103:519-24.

7. Muñoz N., Bosch F. X., Sanjosé S., et al. Epidemiologic classification of human papillomavirus types associated with cervical cancer. N Engl J Med 2003;348:518-27.

8. Schiffman M.H. Epidemiologic evidence showing that human papillomavirus infections causes most cervical intraepithelial neoplasia. J Natl Cancer Inst 1993;85:958-64.

9. Thomas D.B., Ray R.M., Koetsawang A., et al. Human papillomaviruses and cervical cancer in bangkok. I risck factors for invasive cervical carcinomas with human papillomavirus types 16 and 18 DNA. Am. J Epidemiol 2001;153:723-31.

10. Deacan J., Peto J., Yule R., et al. Sexual behaviour and smoking as determinants of cervical HPV infection and of CIN3 among those infected: a case-control study nested within the Manchester cohort. Br J Cancer 2000;88:1565-72.
11. Kjaer S.K., Adriaan J.C., Brule V.D., et al. Different risk factor patterns for high-grade and low-grade intraepithelial lesions on the cervix among HPV-positive and HPVnegative young women. Int J Cancer 1998;76:613-9.

12. Winkelstein Junior R.W. Smoking and cancer of the uterine cervix: Hypothesis. Rev Commen 1977; 106:257-9.

13. Castellsagué X., Bosch F.X., Muñoz N. Environmental co-factores in HPV carcinogenesis. Virus Res 2002;89:191-9.

14. Anttila T., Saikku P., Koskela P., et al. Serotypes of Chamydia trachomatis and risk for development of cervical squamous cell carcinoma. J Am Med Assoc 2001;285:47-51.

15. Smith J.S., Bosetti C., Muñoz N., et al. Herpes simplex virus- 2 as an HPV cofactor in the etiology of invasive cervical cancer: a pooled analysis of the IARC multicentric case-control study. J Natl Cancer Inst ?????

16. Sun X.W., Ellerbrock T.V., Lungu O., et al, Wright T.C. Human papillomavirus infection in human immunodeficiency virus-seropositive women. Obstet Gynecol 1995;85:680-6.

17. Levi J.E., Fink M.C., Canto C.L., et al. Human papillomavirus prevalence, viral load and cervical intraepithelial neoplasia in HIV-infected nomen. Braz J Infect Dis 2002;6:129-35.

18. Bradbier C. Is infection with HIV a risk factor for cervical intraepithelial neolpasia? Lancet 1987;2:1277-8.

19. CDC.1993 Revised classification system for HIV infection and expanded surveillance case definition for AIDS among adolescentes and adults. MMWR: Morb Mortal Wkly Rep 1993;41:1-20.

20. Feingold A.R., Vermund S.H., Burk R.D., et al. Cervical cytology abnormalities and papillomavirus in women infected with human immunodeficiency vírus type 1. J Acquir Immune Defic Syndr 1990;3:396-903.

21. Maiman M. Cervical neoplasia in women with HIV infection. Oncology 1994;8:83-94.

22. Syrjänen K.J., Syrjänen S.M. Papillomavirus infections in human pathology. John Wiley \& Sons Ltda, 2000.

23. Muñoz N., Bosch F. X., Sanjosé S., et al. Epidemiologic classification of human papillomavirus types associated with cervical cancer. N Engl J Med 2003;348:518-27.

24. Bosch F.X., Lorincz A., Muñoz N., et al. The causal relation between human papillomavirus and cervical cancer. J Clin Pathol 2002;55: 244-65.

25. Jian Y., Schmidt-Grimminger D.C., et al. Post-transcriptional induction of 21 cip1 protein by human papillomavirus E7 inhibits unscheduled DNA synthesis reactivated in differentiated keratinocytes. Oncogene 1998; 17:2027-38.

26. Stoler M.H., Schiffman M. Interobserver reproducibility of cervical cytology and histologic interpretations: realistic estimates from ASCUS-LSIL triage study. JAMA 2001;285:1500-5. 
27. Gaffikin L., Ahmed S., Chen Y.Q., et al. Risk factors as the basis for triage in low-resource cervical cancer screening programs. Int $\mathbf{J}$ Gynecol Obstet 2003;80:41-7.

28. Rabelo-Santos S.H., Zeferino L., Villa L.L., et al. Human papillomavirus prevalence among women with cervical intraepithelial neoplasia III and invasive cervical cancer from Goiânia, Brazil. Mem Inst Oswaldo Cruz 2003;98:181-4.

29. Eluf-Neto J., Booth M., Muñoz N., et al. Human papillomavirus and invasive cervical cancer in Brazil. Br J Cancer 1994;69:114-9.

30. Gonçalves M.A., Massad E., Burattini M.N., Villa L.L. Relationship between human papillomavirus (HPV) genotyping and genital neoplasia in HIV-positive patients of Santos City, São Paulo, Brazil. Int J STD AIDS 1999;10:803-7.

31. Cerqueira D.M., Câmara G.N., Da Cruz M.R., et al. Variants of human papillomavirus types 53,58 and 66 identified in central Brazil. Vírus Genes 2003;26:83-7.

32. Maiman M. Management of cervical neoplasia in human immunodeficiency virus-infected women. J. Natl Cancer Inst Monographs 1998:43-9.

33. Palefsky J.M. Cervicovaginal Human Papillomavirus infection in Human Immunodeficiency Virus - 1 (HIV1)-positive and High-risk HIV-Negative women. J Nat Cancer Inst 1999;(91): 226-36. 